\title{
AIDS education could be working, but it is hard to tell
}

Berkeley

THERE is good news and bad news in an Office of Technology Assessment (OTA) report on the effectiveness of AIDS education, released yesterday*. The good news is an unprecedented change in sexual behaviour among homosexuals in San Francisco. The bad news is that education programmes aimed at homosexual men in other parts of the country, as well as efforts to reach intravenous drug users and young people, have been less successful. Moreover, education efforts have not been designed to make it easy to determine which elements are most effective.

The report cites abundant evidence that information alone does not persuade people to reduce their risk of contracting AIDS. In a Pittsburgh study, 91 per cent of homosexuals recognized anal intercourse as the most likely means of contracting human immunodeficiency virus (HIV), and believed that condoms would afford protection, but 65 per cent continued having anal intercourse, and nearly two thirds of those did not use condoms. Such failures are not limited to homosexual men. A San Francisco programme convinced 67 per cent of intravenous drug users that they should sterilize their needles with bleach, although only 15 per cent changed to safer sexual practices.

In contrast, San Francisco homosexuals have shown a dramatic reduction in risky sexual behaviour. From 1985 to 1987 , the proportion of homosexuals engaging in receptive anal intercourse fell from 34 to 8 per cent. Half of the homosexuals in San Francisco are already infected with HIV, but the rate of new infections has dropped to less than 2 per cent per year.

Such dramatic risk reduction requires well-focused education programmes, as well as a shift in community norms, the report says. Programmes aimed at San Francisco homosexual men used extensive market research to find the best way to reach the desired audience, says Thomas Coates, of the University of California, San Francisco, who contributed to the report.

The programmes not only provided information, but also instructed people in behaviour-changing skills, involved community members in the education process

\section{Erratum}

Jacques Beckers has indeed left the US National New Technology Telescope programme (Nature 333, 6; 1988) but not to direct the European Southern Observatory's Very Large Telescope (VLT) project, which is being run by Daniel Enard and Massimo Tarenghi. Beckers will work for ESO on imaging techniques, especially interferometry, which will be an essential element of the VLT. and attempted to develop an environment supportive of behaviour change.

But even such apparently successful programmes have not been rigorously evaluated. The report notes that the success of a programme "may be more a function of the characteristics of the participants than of the programme itself". This is apt for San Francisco, where the homosexual community is well established and is made up primarily of middleclass professionals who may be more likely to be receptive to AIDS education.

According to OTA, little is known about the attitudes and sexual practices of inner-city black homosexuals, and some studies suggest they are less well-informed about AIDS. One Detroit survey found that only 13 per cent of black homosexuals knew that AIDS is transmitted through blood and semen.

OTA recommends carefully aimed educational programmes combining massmedia and face-to-face instruction. But for such a programme to work, the report says its messages must take into account "the language, literacy level, and cultural sensitivities of the people to whom they are targeted". To design an effective educational effort, OTA advises researchers first to acquire a better understanding of the behaviour and attitudes of all AIDS risk groups. The report recommends that the Centers for Disease Control, in collaboration with state governments, should conduct a systematic variation of media messages, followed by an evaluation of their relative effectiveness.

Marcia Barinaga

How Effective is AIDS Education? (Office of Technology Assessment, Washington, DC. June 1988).

\section{Saving Japanese rocks out at sea}

Tokyo copters and launches has begun a $\$ 240$ million operation to salvage two small but vital Japanese rocks poking a few tens of centimetres out of the western Pacific. But all the effort may be in vain.

At high tide the rocks are all that remain above sea level of the coral island of Okinotorishima, Japan's southernmost territory $1,700 \mathrm{~km}$ south of Tokyo. If they are washed away, Japan will lose about 400,000 square kilometres of its 200 -mile exclusive economic zone and with it all rights to fishing and minerals in the area. So an attempt is being made to save the 'island' by building protective walls around the rocks.

But even if the rocks survive, Japan may
A SMALL armada of ships armed with heli- not be able to claim the 200 -mile zone around them. Soji Yamamoto, professor of international law, points out that article 121 of the yet-to-be-ratified United Nations Law of the Sea Convention states that "rocks which cannot sustain human habitation or economic life of their own shall have no exclusive economic zone".

Yamamoto suggests that, if Japan wants to press a claim, a lighthouse, wireless station and port should be installed on the island before the convention comes into effect ( 36 developing nations have signed the convention but 60 must sign for ratification and developed nations are at present holding out). "Territory is not something that exists naturally", Yamamoto says, "it must be obtained by a country's efforts".

David Swinbanks

\section{IMAGE UNAVAILABLE FOR COPYRIGHT REASONS}

Ships surround Okinotorishima while a helicopter lowers an iron tripod onto a wave-breaking wall of tripods being built around one of the island's two remaining rocks. After the two little 'islands' have been surrounded with walls $50 \mathrm{~m}$ in diameter, the enclosed areas will be partially infilled with concrete to reinforce the walls. But care must be taken not to pave over the rocks with concrete, because under international law they would then be disqualified as parts of a natural island. The rocks, both of which are eroded at the base, must stand on their own (Asahi Shimbun Photo Service). 